\title{
DEPRESYON, UMUTSUZLUK, SOSYAL BEĞENIRLIK VE KENDINI KURGULAMA DÜZEYININ INTIHAR FIKIRLERI ILE iLişKisi
}

\author{
Soda HARAN", Orhan AYDIN-
}

Gunluk dılde kendı yaşamına son verme anlamına gelen ıntihar çok eskıden berı sokaktakı adamdan ınsanla ılgıı bılım dallarında çalışanlara kadar herkesın ılgısını çekmış ve bır yandan etık ve dını açıdan tartşııııken dığer yandan bııımsel çalış. malara konu olmuştur

Intıhar stres yaratan yaşam koşullarına tepkı veren "normal" bıreylerden ağır ruhsal sorunları olan hastalara kadar uzanan genış bır kıtlede görulebılmektedir Bu nedenle intihar riskı taşıyan bıreylerın belırlenmesı ve gereken ontemienn alınması sağlık alanında çalışan uygulamacıların karşılaştığı temeł bır sorun olmaktadır Bu soruna çơzum bulmak amacıyla ıntıhar davranışını yordayabılecek değışkenlerin neler oiduğu yoğun bır biçımde araştırılan bır konu olmuştur Bu araştırmaların sonuçlarına gơre inthar ve intıhar gırışımlerını yordayan en onemlı değışkenlerden bırı intıhar fikırlerıdır (Hughes ve Neımyeyer 990) Intihardan soz eden kışılerın ıntıhar etmeye nıyetlerı olmadığı yolundakı yaygın kanının aksıne, intıhar gııışımınde bulunan kışiterden yaklaşık $\% 50$ le 80 arasinda değışen bır oranın bu fıkırlen açık ya da ustu ortulu bır bıçımde çevrelernne llettıklen saptanmıştır (Lester ve Lester 1971) Intıhar duşunulmeye başlandığında bunu her insanın ıçınde varolan kendını koruyucu ve kendını yıkıcı guçler arasındakı çatışma ızler Bu nedenle, intıhar fikırlesı kışıy! tehdıt eden çatışma ve krız durumlarının en ıyı gostergesı olarak kabul edimektedir (Poldinger 1989)

\footnotetext{
- Uzm Psk A U Psıkıyatrık Krız Uygulama ve Araştırma Merkezı

* Prof Dr HU Edebıyat Fakultesı Psıkolojı Bolumu
}

Depresyon ıntıhar nskını arttıran psıkıyatnk hastalıkların başında gelmektedır Depresyonların genel populasyondakı intıhar rıskını 30 kat arttırdığı ılerı surulmektedır (Guleç 1989) Ayrıca çeşıtı psıkıyatrık hastalıklar arasında ıntınar oranı en yuksek olan grubun depresıfler olduğu bilınmektedır (Beck 1973, Fawcet 1987, Hawton 1987, Blumenthal 1988, Wolfersdort 1990)

Geleceğe ilışıın olumsuz beklentıler olarak tanımlanan umutsuzluk depresyonla yakından ılışkılldır Intrhar nyetı lle depresyon arasındakı itışııde umutsuzluk krıtık rol oynamaktadır Intıhar eğlımı kışı Intıharı kendı umutsuz ve çozumsuz durumu ıçin olası tek çozum yolu olarak gorur Yapılan bir çok araştırmada depresyon intıhar ve umutsuzluk arasında yakın bır Ilıskının olduğu ve umutsuzluğun bu davranışları depresyondan daha iyı yordadiğı bulunmuştur (Beck, Kovacs, ve Weissman 1975, Beck, Brown ve Steer 1989, Wetzel ve ark 1980 , Mınkoff ve ark 1973, Wetzel 1976. Ranerı ve ark 1987)

Bıreylerın kendılen hakkında sorulara verdıklerı yanıtların soruların ıçerı̆ı dışındakı bazı etkenler taraftndan etkılendıklerı uzun zamandan berı bilnen bır olgudur Bu etkenler arasında en genış ıgı. yı uyandıran, bıreylerın kendılerını beğenılen ya da istenılen ozellıklere sahıp olarak gosterme eğılımlendir "Sosyal begenırlik etkisi" olarak adlandırılan bu eğılım hem ôlçmenın geçerlılığını tehdıt eden bır sorun hemde başlı başına bir kışılık boyutu olarak çok sayıda araştırmaya konu olmuştur Son yiliar. da yapılan bazı araştırmalarda sosyal beğenırlık 


\begin{tabular}{llll}
$K$ & $R$ & $I$ & $Z$ \\
\hline
\end{tabular}

depresyon ve umutsuzlukla birlikte ele alinmış ve bu değişkenlerden bağımsız olarak intiharı yordayıcı bir niteliğe sahip olup olmadığı incelenmiştir. Ancak bu araştırmalarda elde edilen bulgular arasinda bir tutarlılık bulunmamaktadır.

"Kendini kurgularna" (self-monitoring) kavramı bireylerin davranışlarını sosyal ortamların gereklerine göre düzenleyerek bașkalarının kendileri hakkında oluşturduklart izlenimleri denetleme eğilimlerine işaret etmek için kullanılmaktadır (Synder 1982).

Syndere (1982) göre, kendini kurgulama davranışı açısından bireyler arasında onemli farklılıklar vardır. Kendini kurgulama düzeyi yüksek bireyler sosyal onay ve başkalarının üzerinde bıraktıkları izlenimlerle daha fazla ilgilenmekte, buna bağlı olarak da sosyal ortamlarda kendi içlerinden geldiği gibi değil, ortamın gereklerine ya da etkileşimde bulundukları kişilerin isteklerine uygun biçimde davranma eğilimi göstermektedirler.

$\mathrm{Bu}$ araştırma depresyon, umutsuzluk, sosyal beğenirlik ve kendini kurgulama düzeyi ile intihar fikirleri arasındaki ilişkileri normal ve krizde bulunan deneklerde karşılaştırmalt olarak incelemek ve normal ve kriz gruplarında intihar fikirlerini bu değişkenlerden hangisinin daha iyı yordadığını belirtemek amacıyla düzenlenmiştir.

\section{YÖNTEM}

Denekler: Araştırma "kriz grubunu" oluşturan 80 denek ve "normal grubu" oluşturan 80 denek oimak üzere toplam 160 kişiyle yürütülmüştür. Kriz grubu stres yaratan yaşam olaylarıyla karşı karşıya kalan ve olağan sorun çözme davranışlarıyla bu olayların üstesinden gelemeyen bireylerden oluşmaktadır. Bu bireylerin kriz merkezine başvuru nedenlerine bakıldığında sorun alantarının evlilik ve eş, aile üyeleri, arkadaş ve karşı cinsle ilişki, sağ. lık, iş, okul, ekonomik sorunlar ve kayıplar biçimin. de gruplanabildiği görülmektedir. Ağır psikopatoloji gösteren (şizofreni, paranoya, organik bozukluklar, alkol bağımılıı̆ı) bireyler çalışma kapsamı içine alınmamıştır.

\section{VERI TOPLAMA ARAÇLARI}

BECK DEPRESYON ÖLÇEĞ: Depresif kişilerde yaygınlıkla kendilik değerinin azalmasına ilişkin befirtileri ölçmek amacıyla Beck (1961) tarafından geliştirilmiştir. 21 maddeden oluşan blçøkteki maddeler 0 dan 3'e kadar depresyonun ciddiyetine göre sıralanınıştır. Ölçekten alınabilecek puanlar 0 ile 63 arası deģişmekte ve yüksek puan depresif belirtilerin çokluğuna işaret etmektedir.

BECK UMUTSUZLUK ÓLÇEĞl: Beck ve arkadaşları tarafından bireylerin geleceğine ilişkin karamsarlık derecelerini belirlemek amacıyla geliştirilmiştir. "gelecek ile ilgili duygular" "güdü kaybı" ve "geleceğe ilişkin belirtiler" olmak üzere 3 faktorr içeren bu olçek 11 doğru ve 9 yanlış anahtar cevabı olan 20, maddeden oluşmaktadır. Ölçekten ailınabilecek puanlar 0 ile 20 , arasında değișmekte ve yüksek puan umutsuzluk derecesinin fazla olduğunu göstermektedir.

KENDINI KURGULAMA ÖLÇEĞ: Bu ठlçek Synder (1974) tarafından geliştirilen 25 maddelik kendini kurgulama ơlçoğinin daha sonra Synder ve Gongestad (1986) tarafından yeniden düzenlenerek 18 maddeye indirilmiş son şeklidir. Maddeler "Doğru- Yanlış" biçiminde yanıtlanmakta, kendini. kurgulama yonündeki yanıtlara 0 , puan verilmektedir. Ölçekten alınabilecek en düşük puan 0 , en yüksek puan 18 olup, yüksek puan kendini kurgulama đüzeyinin yüksek olduğuna işaret etmektedir.

SOSYAL BEGENIRLIK ÖLÇEĞl: Kozan (1983) tarafından geliş̧irilen ölçek "doğru-yanlış" biçiminde işarettenen 20 maddeden oluşmaktadır. Olçeğj puanlayan kişi sosyal beğenirlik yőnünde verdiği her yanıt için bir puan almaktadır. Puanlar 0, 20 arasında değişmekte olup yüksek puan sosyal beğenirlik eğiliminin yüksekliğine işaret etmektedir.

INTIHAR FIKIRLERI ÖLÇEĞi: Linehan ve Nieisen'in $(1981,83)$ geliştirdiği 25 maddeden oluşan Intihar Davranışları Ölçeğinden (Suicidal Behavior Questionnaire) araştırmanın amacına uygun olarak alınan 4 maddeden oluşmaktadır. Ölçekten alınabilecek en yüksek puan 17 en düşük puan ise 3 olup, yüksek puan intihar fikirlerinin varlığına işaret etmektedir.

\section{IŞLEM}

Araştırma kapsamına alınan kriz grubundaki deneklere ölçekler bireysel olarak uygulanmıştır. Normal denekler ise bilgi formunda verilen bilgiler dikkate alınarak, kriz grubundaki deneklere benzer ozeliliklere sahip olan 80 tanesi seçilerek araştırma kapsamına alınmıştır. 


\section{BULGULAR}

Araştırmanın amacı doğrultusunda olç̧eklerden elde edilen veriler Pearson Momentler çarpımı korełasyon, $t$ test ve Aşamalı Regresyon teknikleri kullanılarak analiz edilmiştir.

Araştırmada yanıtlanması amaçlanan sorulara ilişkin bulgular şరyle ozetlenebilir.

Soru 1: Depresyon düzeyi ile intihar fikirleri arasında bir iliş̧ki varmıdır? varsa bu ilişkinin derecesi incelenen grubun normal ya da kriz olmasına bağlı olarak değişmekte midır?

Tablo 1: Deneklerin Depresyon ve Inthar Fikırlen Puenlarının Ortalama ve Standart Sapmaları 由e Bu Puanlar Arasındakı Korelasyon Katsayıları

\begin{tabular}{|c|c|c|c|c|c|}
\hline $\begin{array}{l}\text { Puan Turu } \\
\text { Gruplar }\end{array}$ & \multicolumn{2}{|c|}{$\frac{\text { Depresyon }}{\mathrm{X}} \mathrm{S}$} & \multicolumn{2}{|c|}{ 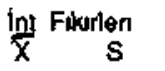 } & $\begin{array}{l}\text { Korelasyon } \\
\text { Katsayıları }\end{array}$ \\
\hline $\begin{array}{l}\text { Normal } \\
\text { Knz Grubus } \\
\text { Tum Denekler }\end{array}$ & $\begin{array}{l}687 \\
2197 \\
1442\end{array}$ & $\begin{array}{l}612 \\
1058 \\
1147\end{array}$ & $\begin{array}{l}361 \\
650 \\
516\end{array}$ & $\begin{array}{l}154 \\
339 \\
295\end{array}$ & $\begin{array}{l}41^{*} \\
53^{*} \\
63^{*}\end{array}$ \\
\hline
\end{tabular}

${ }^{*} \mathrm{P}<001$

Ortalamalar arasında yapılan karşılaş̧ırmalar krı grubu deneklerin hem depresyon puanlart ortalamasının $(t=11.04, s . d=158, p<.001)$ hemde inthar fikırlen puanlarının ortalamasının normal deneklerinkınden anlamí düzeyde yưkssek oldugunu gostermıştir.

Soru 2: Umutsuzluk düzeyı ile intthar fıkırleri arasında bir ilişki varmıdır? Varsa bu ilişkinın derecesi incelenen grubun normal ya da kriz grubu oimasına bağh olarak değışmektemidir?

Tablo 2: Deneklenn Umutsuzluk ve İntihar Fukurler Puanlarınun Ortalama Standart Sapmalari te Bu Puanlarin Arasindaks Korelasyon Katsaylları

\begin{tabular}{|c|c|c|c|}
\hline $\begin{array}{l}\text { Puan Türü } \\
\text { Gruplar }\end{array}$ & $\frac{\text { Umutsuzluk }}{\mathrm{x}} \stackrel{\mathrm{s}}{\mathrm{s}}$ & $\frac{\text { Int Fikirlen }}{x} \underset{S}{S}$ & $\begin{array}{l}\text { Korelasyon } \\
\text { Katsayları }\end{array}$ \\
\hline $\begin{array}{l}\text { Nomal } \\
\text { Knz Grubu } \\
\text { Tum Denekler }\end{array}$ & $\begin{array}{ll}346 & 27 \\
849 & 52 \\
598 & 486\end{array}$ & $\begin{array}{l}381 \\
650 \\
516\end{array}$ & $\begin{array}{l}21^{*} \\
52^{* *} \\
59^{* *}\end{array}$ \\
\hline
\end{tabular}

*Ps $005 \quad$ **P< 001

Görüldūgü gibi umutsuzluk lle intihar fikırleri arasında elde edilen korelasyon katsaylları hem tüm denekler ıçın $(r=.59, P<.001)$ hemde normal $(r=21, P<.05)$ ve $k r i z \quad(r=.52, p<.001)$ denek grupla- rnda anlamlıdır. Bu sonuçlar umutsuzluk ile intihar fikirleri arasında anlamlı bir pozıtif ilişkinin bulundugunu gőstermektedir. İki gruptan elde edilen korelasyon katsayılarına (.21 ve .52) uygulanan manidarlik testi bu iki katsayı arasındaki farkın anlamiı oldugunu göstermiştir $(z=2.26, p<.01)$. Bu sonuç ise umutsuzluk ile intıhar fıkirlerı arasındaki iliş̧kinin kriz grubunda daha anlamlı olduğunu gostermektedir. Ortalamalar arasındakı farka bakıldığında kriz grubundakı deneklerin umutsuzluk düzeylerinin kuvvetli dozeyde daha yüksek olduğunu göstermiştir. $(t=7.60,5 . d .=158, p<.001)$.

Soru 3: Sosyal beḡenirlik eğilimi ile intihar fikirleri arasında bir ilişki var mıdır? Varsa bu jlişkinin derecesi, incelenen grubun normal ya da kriz grubu olmasına bağlı olarak deģişmektemidir?

Tablo 3: Deneklertn Sosyal Begenurhk ve Inthar Fikurlen Puanlarının Ortalama ve Standart Sapmaları le Bu Puanları Arasındakı Korelasyon Katsayları

\begin{tabular}{|c|c|c|c|}
\hline $\begin{array}{l}\text { Puan Turŭ } \\
\text { Gruplar }\end{array}$ & $\operatorname{Sos}_{\mathrm{X}}^{\mathrm{Beg}}$ & $\frac{\text { Int Fikurlen }}{\mathrm{x}} \stackrel{\mathrm{s}}{ }$ & $\begin{array}{l}\text { Korelasyon } \\
\text { Katsayiları }\end{array}$ \\
\hline $\begin{array}{l}\text { Normal } \\
\text { Kriz Grubu } \\
\text { Tom Denekler }\end{array}$ & $\begin{array}{ll}1250 & 394 \\
1160 & 403 \\
1205 & 401\end{array}$ & $\begin{array}{l}1154 \\
339 \\
295\end{array}$ & $\begin{array}{l}-14 \\
-20 \\
-21^{*}\end{array}$ \\
\hline
\end{tabular}

* $P<05$

Tüm denekler içın hesaplandığında, sosyal beğenirlık eğılımıerı tle intıhar fikırleri arasında anlamı bir negatıf ilişkı bulunmuştur $(r=\cdot 21, p<.05$ ) Ancak, normal ve kriz grubu deneklerı ıçın yapılan ayrı ayrı hesaplamalarda bu lişkinin anlamlık düzeyine ulaşmadığı görülmüştür.

Soru 4: Kendinı kurgulama düzeyi ile intihar fikirleri arasında bir ilışki var mıdır? Varsa bu iliş̧kinin derecesi incelenen grubun normal yada kriz grubuolmasına bağlı olarak değışmektemidir?

Tablo 4: Deneklernn Kendın Kurgulama ve Intıhar Fikurlerı Puanlarının Ortalama ve Standart Sapmaları le Bu Puanları Arasındaki Korelasyon Katsayları

\begin{tabular}{|c|c|c|c|c|c|}
\hline $\begin{array}{l}\text { Puan Turū } \\
\text { Gruplar }\end{array}$ & $\frac{K e n}{x}$ & $\begin{array}{r}\text { Kur } \\
s\end{array}$ & $\frac{\ln t}{x} \mathrm{FI}$ & & $\begin{array}{l}\text { Korelasyon } \\
\text { Katsayları }\end{array}$ \\
\hline $\begin{array}{l}\text { Normal } \\
\text { Kriz Grubu } \\
\text { Tüm Denekler }\end{array}$ & $\begin{array}{l}645 \\
675 \\
660\end{array}$ & $\begin{array}{l}250 \\
330 \\
291\end{array}$ & $\begin{array}{l}381 \\
650 \\
516\end{array}$ & $\begin{array}{l}154 \\
338 \\
295\end{array}$ & $\begin{array}{l}14 \\
05 \\
09\end{array}$ \\
\hline
\end{tabular}

Tablodan görülebileceği gıbı deneklerın bu iki ð૪।çøkten aldıkları puanlar arasında hesaplanan kore- 
lasyon katsayılarının hiçbiri anlamlı değildir. Ayrıca normal ve kriz grubu deneklerin kendini kurgulama ölçeğinden aldıkları puanların ortalamaları arasında da anlamlı bir farklılık bulunmamaktadır.

Soru 5: Normal ve kriz grubu deneklerde intihar fikirlerini depresyon, umutsuzluk, sosyal beğenirlik ve kendini kurgulama değişkenlerinden hangisi daha iyi yordamaktadır?

Tablo 5: Normal Deneklerde htihar Fikirierinin Yordanmasına ligikin Assamalı Regresyon Analizi Sonuçları

\begin{tabular}{|lcccccc|}
\hline $\begin{array}{l}\text { Yordayict } \\
\text { Degişken }\end{array}$ & R & R & $\begin{array}{c}\text { R deki } \\
\text { arths }\end{array}$ & $\begin{array}{c}\text { Yor. St } \\
\text { Hatasi }\end{array}$ & Beta & F \\
\hline Depresyon & .40997 & .16808 & .16809 & 1.4167 &, 40997 & $15.76^{*}$ \\
\hline
\end{tabular}

pe, 001

Normal deneklerden oluşan grupta intihar tikirlerinin yordanmasına anlamlı düzeyde katkıda bulunan tek değişken depresyondur.

Tablo 6: Kriz Grubunda Intihar Fikirlerinin Yordanmasına liş̧in Aşamaiı Regresyon Analizi Sonuçlan.

\begin{tabular}{|lcccccc|}
\hline $\begin{array}{l}\text { Yordayıc। } \\
\text { Degişken }\end{array}$ & R & R & $\begin{array}{c}\text { R deki } \\
\text { artış }\end{array}$ & $\begin{array}{c}\text { Yor. St } \\
\text { Hatas। }\end{array}$ & Beta & F \\
\hline Depresyon & .52967 & .28056 & .28056 & 2.89 & .32 & $30.42^{*}$ \\
Umutsuzluk & .5778 & .33394 & .059 & 2.80 & .31 & $19.30^{\circ}$ \\
\hline
\end{tabular}

$\cdot p<.001$

Kriz grubundaki deneklere intihar fikirlerinin yordanmasina anlamlı katkllarin depresyon ve umutsuzluk değişkenlerinden geldiği görülmektedir.

\section{TARTIŞMA}

Araştırmada elde edilen bulgular normal deneklerde intihar fikirlerinin hem depresyon hemde umutsuzlukla ilişkili olduğunu göstermiştir. Ancak bu grupta depresyon ile intihar fikirleri arasında elde edilen korelasyon katsayısının oldukça yüksek olmasina ve regresyon analizinde depresyo. nun bu fikirleri yordayabilen bir değişken olarak gö-

\section{KAYNAKLAR}

Beck, A.T., D. Lester (1973) Components of Depression in Attempted Suicide. The Journal of Psychology, 85:257-260.

Beck, A.T. M. Kovacs, A. Weissman (1975) Hopelessness and Suicidal Behavior. Jama. 134. 11:1146-1149. rünmesine karşın intihar fikirleri ile umutsuzluk arasında elde edilen korelasyon katsayısı oldukça düşük çıkmış ve regresyon analizi sonuçlan umutsuzluğun intihar fikirlerini yordayıcı bir degerinin olmadığını ortaya koymuştur. Dolayısıyla normal bireylerde intihar fikirlerini belirleyen temel değişkenin depresyon olduğunu sőylemek daha emin bir yol gibi görünmektedir.

Normal grupta olduğu gibi kriz grubunda da intjhar fikirlerinin hem depresyon hemde umutsuzlukla ilişkili olduğu górülmüştür. Ancak normal gruptan farklı olarak, depresyon ve umutsuzluk ile intihar fikirleri arasında elde edilen korelasyon katsayısının daha yüksek olması regresyon analizinde depresyonun ilk değişken olarak ortaya çıkması, kriz grubunda intihar fikirlerinin oncelikle depresyon düzeyi tarafından belirlendiğine işaret etmektedir.

İtihar fikirlerinin sosyal beǧenirlik ve kendini kurgulama düzeyi ile olan ilişkileri ne normal ne de kriz grubunda anlamlı çıkmamıştır. Bununla birlikte, tüm denekler birarada değerlendirildiğinde, intihar fjkirlerinin sosyal beğenirlikle olan ilişkisinin anlamlı olduğu görülmüş ve kriz grubunda söz konusu iki değiş̧en arasında anlamlıık düzeyine çok yakın bir ilişki bulunmuştur. Bu nedenle, krizdeki bireylerde intihar fikirleri-sosyal beğenirlik ilişkisini açığa çıkarmak amacıyla araştırmalar yürütülmesinin uygun olacağı düşünülmektedir.

Bu araştırnada elde edilen ve krizdeki bireylerde intihar fikirlerinin depresyon ve umutsuzlukla ilişkili olduğunu gösteren bulgular pratik bir önem taşımaktadır. Kriz durumu bir yandan bireye kendini geliştirme şans; veren, diğer yandan bir ruh hastalığına yakalanma olasılığını arttıran geçici bir durumdur. Bu nedenle kişi bir dönüm noktasında bulunmaktadır. Bu durumdaki bir kişinin intiharı bir çözüm yolu olarak görebileceği olasılı̆̆ı klinisyenler tarafından dikkatle değerlendirilmelidir. Bu araştırmadan elde edilen sonuçlar kriz durumundaki bireylerde intihar riskini değerlendirirken, óncelikle depresyonun, depresyonun yanısıra umutsuzluk düzeyinin dikkate alınması gerektiğine işaret et: mektedir.
Beck, A.T., R.A. Steer (1989) "Clinical Predictors of Eventual Suicide: A 5 to 10 year Prospective sudy of Suicide Atempters" Journal of Affecive Disorders 17:203-209.

Blumenthal, S.J. (1988) Suicide= A Guide to Risk Factors, Assesment and Treatment of Suicidal Patients Medical Clinics of North-America 70, 4. July:: 937-971. 
Güleç, C. L. Küey (1989) Türkiye'de 1980terde Depresyon: Epidemiyolojik ve Klinik Yaklaşımlar Noro-Psikiyatri Arşivi 24. Ozel sayl:17-28.

Hawton, K. (1987) "Assesment of Suicide Risk." Bititish Journat of Psychiatry 150:145-153.

Hughes, S.L. R.A. Neimeyer (1990) "A Cognitue Model of Suicidal Behavior" D. (ed), Current Concepts of Lester. Suicide. Philadelphia. The Charles Press Publishers, Inc., 1-28.

Kozan K. (1983) Davranış Bilimleri Araştırmalarında Sosyal Beğgenirlik Boyutu ve Türkjye için bir Sosyal Beğenirlik Olçegj ODTU Geliştirme Dergisi 10,3:447.478.

Lester, G.D. Lester (1971) Suicide: The Gamble With Death. New Jerscy, Prentice-Hall, Inc.

Linehan, M.M. S.L. Nielsen (1981) "Assesment of Suicide Ideation and Parasuicide: Hopelessness and Social Desirability" Joumal of Consulting and Clinical Psychology 49. 5=773-775.

Linehan, M.M. S.L. Nietsen (1983) "Social Desirability: Its Relevance to the Measurement of Hopelessness and Suicidal
Behavior". Joumal of Consulting and Clinical Psychology, $51,1: 141-143$.

Minkoff, K ve ark. (1973) Hopelessness, Depression and Attempted Suicide American Journal of Psychiatry 130, $4: 4$.

Pöldinger, W.J. (1989) "The Psychopathology and Psychodynamics of self-destruction." Crisis 10,2: 113-122.

Ranieri W.F. ve ark. (1987) Relationships of Depression, Hopelessness and Dysfunctional Attitudes to Suicide lacation in Psychiatric Patients. Psychological Reports, 61 \$67.975.

Snyder, M. (1974) The Self-Monitoring of Expressive Behavior. Journal of Personality and Social Psychology 30: 526-537.

Synder, M. (1982) Choasing Social Situations: Two Investigations of Self-Monitoring Processeses Joumal of Personality and Social Psychology 18:165-183.

Wetzel, R. ve ark. (1900) Hopelessness Depression and Suicide Intent Jownal of Clinical Psychiatry. 41, 5:159-169.

Wolfersdorf. M. ve ark. (1990) Suicide Risk in Suicidal Versus Nonsuicidal Depressed inpatients. Crisis XII!, 2-85-97. 